Article

\title{
Remanufacturing and surface modification in micro-areas by laser beam and microTIG methods
}

\author{
Przemysław Połaski ${ }^{1, *}$, Jerzy Jakubowski ${ }^{1}$ \\ ${ }^{1}$ Warsaw University of Technology \\ Jerzy Jakubowski, Ph.D., j.jakubowski@wip.pw.edu.pl \\ * Correspondence: Przemysław Połaski, M.Sc.; przemyslaw.polaski.dokt@pw.edu.pl
}

Received: 02.10.2019; Accepted: 22.01.2020

\begin{abstract}
Over the past years, intensive development of welding technologies that enable precise impact on the workpiece has been observed. The laser technology is the most known and commonly used tool for precise machining, both in terms of obtaining the appropriate geometry and heat distribution. This technology is now easily available, but it still has many limitations in its "basic edition". An attractive alternative in machining micro-areas can be the arc method - microTIG, which is a modification of the TIG method. The work compares the effects of cladding of selected pairs of substrate materials using the microTIG method and a laser beam. The results of microscopic tests and hardness measurements of deposits made with a laser beam and the microTIG method are presented. The advantage of cladding with the microTIG method was the possibility of obtaining deposits with a lower dilution of the substrate material in the clad weld compared to laser cladding. On the other hand, clad welds produced with the laser beam had a significantly smaller amount of welding defects.
\end{abstract}

Keywords: laser cladding; micro-areas; microTIG method

\section{Introduction}

In technics mainly two methods to extend the service life of technical objects such as tools and devices are used. The first is surface modification. The purpose of surface modification processes is most often to change certain surface properties relevant to the operating conditions of a given product. Over the years, many surface modification methods have been developed that are most often used to change the properties of large surface fragments, e.g. thermal spraying or quenching processes. Most often, however, there is no need of treatment of the entire surface of the element. The area of the treated material can be limited to a small area, which is a working element of a given product. This type of approach is evident in the production of machining tools in which only a small part of the tool is made of wear-resistant material.

The original geometry and operational properties of tools and machine parts can be reproduced using regeneration treatments. Regeneration can be carried out both in macro and micro scale using appropriate methods and process parameters [1].

Surface modification or regeneration in micro-areas can be carried out using micro-plasma technologies [2]. Microplasma arc machining with low currents and high energy concentration enables precise heat dosing to the treatment area. Thanks to this, it is possible to modify a number of properties of the surface layer (e.g. hardness) by selective interaction with a concentrated arc [3]. In the event that the heat treatment does not allow to obtain the required material properties, surface modification can be carried out using material supplied from the outside. An example of such a process is micro-plasma spark alloying. In this process, the source of additional material is the electrode, whose composition is selected depending on the required properties of the surface layer [4]. In the case where it is required to produce a layer of greater thickness, well bonded to the substrate and with better mechanical, tribological or chemical resistance properties than the substrate material, plasma cladding processes are used [5].

Another commonly known and used method of cladding is the TIG (Tungsten Inert Gas) method. As in the case of cladding using a plasma arc, the TIG method allows obtaining a metallurgical connection of the substrate with the applied layer [6]. The use of this technology for machining in micro-areas is possible, however, it requires limiting the effect of the heat of the electric arc on the substrate material. This is especially important when it is required to obtain the lowest possible dilution ratio. One of the solutions limiting the influence of heat on the base material and ensuring the stability of the cladding process is the 
use of additional cooling of the base material while supplying the arc with DC current [7]. The effect of heat can also be reduced by decreasing the duration of the electric arc on the ground. The electric arc in the classical TIG method works in a continuous or pulsating way. However, an impulse (with complete arc quenching) method of work is also significantly reducing the effect of heat on the material. This technology was adopted as microTIG [8]. It has been presented and applied in this work.

In addition to arc technologies for surface modification, beam technologies, in particular laser technologies, play an important role. Depending on the requirements, laser surface treatment can be carried out without additional material [9] or with additional material in the form of powder or wire fed into the laser beam area. The advantages of laser technology in the context of cladding include high heat energy density, high precision machining with the possibility of its automation and the possibility of obtaining a very narrow heat affected zone [10]. The small dimensions of the liquid metal pool that is being formed cause that the cooling speeds are high and exceed $1000 \mathrm{~K} / \mathrm{s}$, which allows the formation of structures with very good mechanical properties in the welds [11]. Heat treatment may not always involve an increase in the surface properties of the surface layers. The impact of a heat source, e.g. a laser beam, may have the benefit of improving the machining conditions of hardened materials, e.g. as a result of the nitriding process [12].

Micro-scale machining techniques for complex objects can include resistive-pulse cladding. Together with the selection of the appropriate material, this method allows the production of layers of high hardness with minimal influence on the base material [13]. The application possibilities of micro-cladding techniques are very large. For example, the laser beam can be used as a heat source for cladding the combustion engine exhaust valves [14] or in medicine for marking stents (made of shape memory alloys) with metallic markers [11]. In turn, the microTIG method has been used in the aviation industry to regenerate thin titanium sensors, for which it is required to limit the amount of heat introduced and to obtain narrow weld beads [15]. Another example of the application of this method is welding elements of car battery cells used in electric vehicles [16] or regeneration of matrix edges in hard to reach areas where the mobility of the operator's hand movements allows reaching certain places in a more efficient and faster way [17].

The paper presents the results of tests and comparison of the effects of cladding in micro-areas of selected pairs of base materials and additional materials using a laser beam and an alternative method of microTIG cladding.

\section{Characteristics of the microTIG method}

In the microTIG method, the heat source is an electric arc glowing between the non-consumable electrode and the stock, similar to the TIG method. The binder is fed by hand, using a special wire feed holder (Fig. 1). The handles (containing a non-consumable electrode) used in the microTIG method are designed so as to enable impulse rather than continuous arc operation. In addition, similarly to the TIG method, surface treatment is carried out in an inert gas shield, usually argon. The impulse nature of the device's operation makes it possible to significantly reduce the amount of heat introduced into the stock, which is very important for applications in the microscale. At the same time, precise metering of the amount of heat input facilitates the machining of materials sensitive to overheating. The research used a device under the trade name piggyWelder ${ }^{\circledR} 3$ power enabling work with an impulse arc. Figure 2 shows an experimental stand equipped with a microTIG device with additional instrumentation. In addition to the microTIG device, one of the most important devices included in the workstation is an optical microscope, which significantly increases the precision of microscale surface treatment.

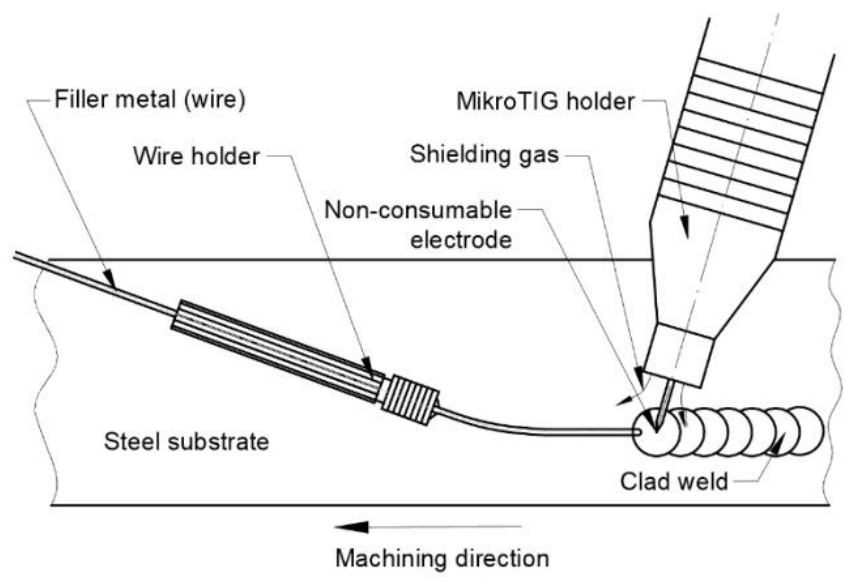


Fig. 1. Diagram of the microTIG hardfacing process

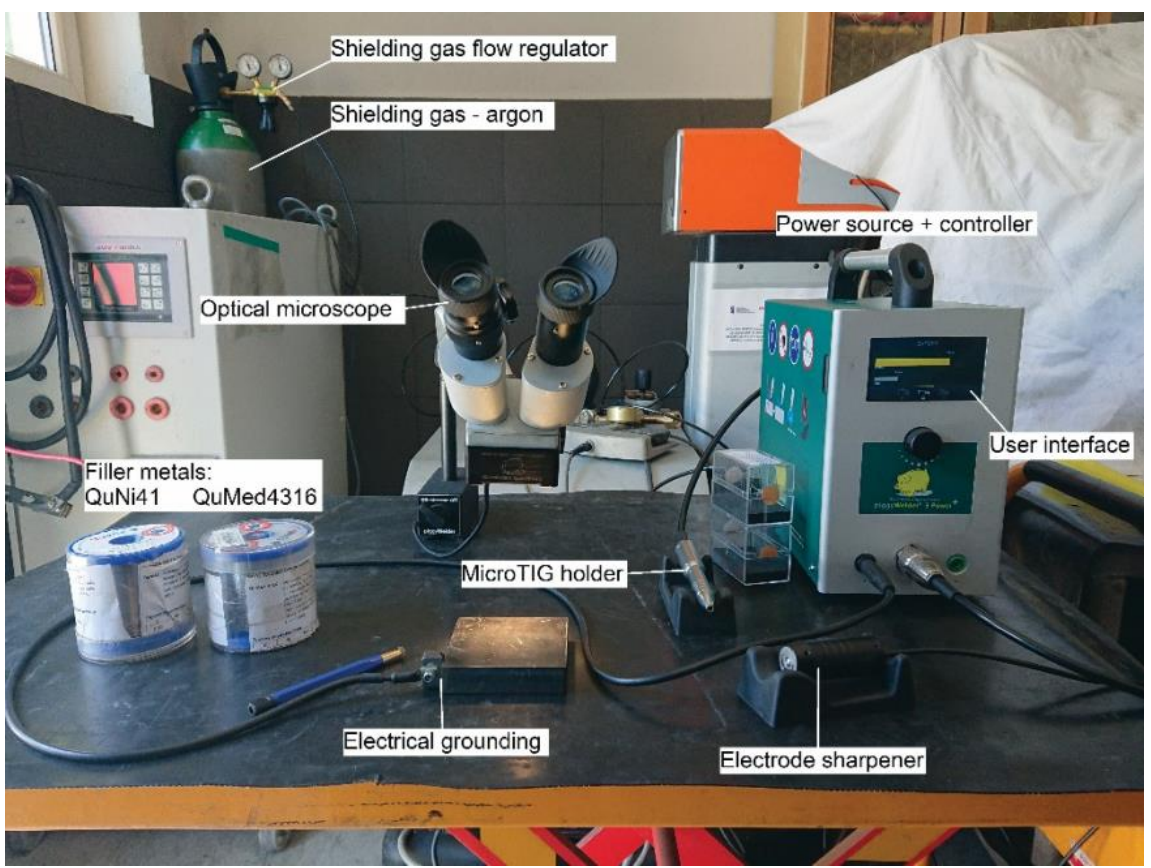

Fig. 2. Photograph of applied cladding system equipped with microTIG device

\section{Characteristics of cladding using a pulse laser}

Laser radiation is a special case of electromagnetic radiation. The generation of the laser beam is possible due to the phenomenon of stimulated emission that takes place in the laser device resonator. Laser radiation is characterized by a small beam divergence, coherence and monochrome, which means that a given laser beam emits radiation of a constant wavelength [18]. The wavelength of the radiation emitted by the laser depends on the type of active medium. A solid-state laser with an impulse character of work was used in the research. The active medium contained in the resonator was a rod made of $\mathrm{Y}_{3} \mathrm{Al}_{5} \mathrm{O}_{12}$ yttrium-aluminum garnet with an admixture of $\mathrm{Nd}_{2} \mathrm{O}_{3}$ neodymium oxide $(0.8 \div 1.5 \%$ by mass). The wavelength of radiation emitted by this laser is about $1.06 \mu \mathrm{m}$ [18].

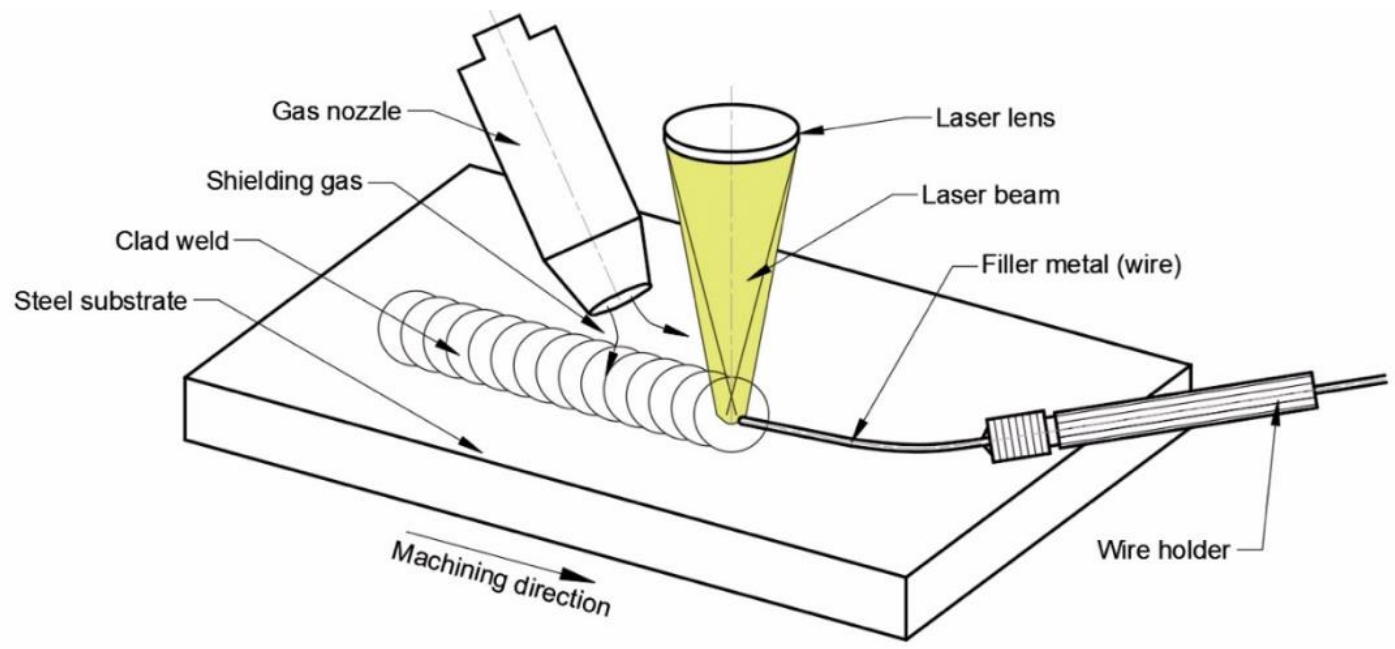

Fig. 3. Diagram of the pulsed laser cladding process

The course of the cladding process using a pulse laser is similar to that of the microTIG method. Both surface modification processes in the microTIG microareas and the pulse laser are carried out manually. In the case of the laser method, the electronic system is responsible for interpreting the user's movements/commands, and then performs a direct movement of the laser head in accordance with these instructions. A common feature of these methods is also manual feeding of additional material to the machining area. A diagram of the cladding process is shown in figure 3 . In turn, figure 4 presents a 
photograph of an experimental station equipped with an EVO Mobile pulse laser with a maximum pulse power of $13 \mathrm{~kW}$, which was used in the tests.

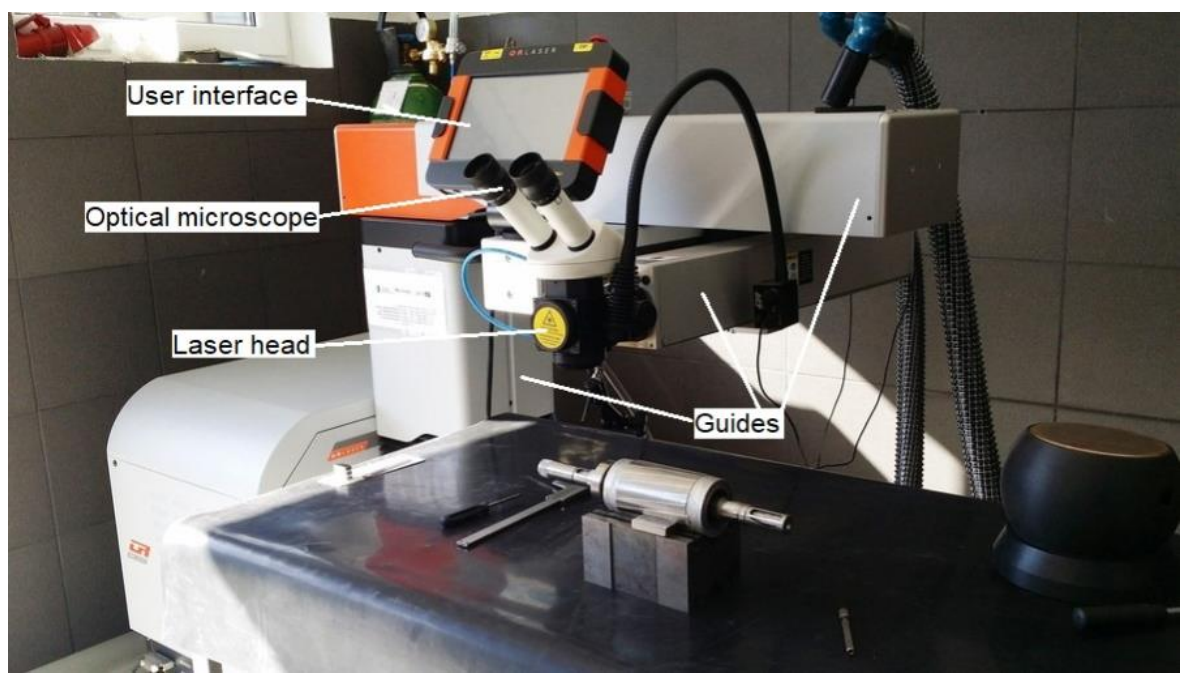

Fig. 4. Stand for laser cladding, OR Laser EVO Mobile device

\section{Materials used for the research}

Special steels have been used as the base material, which are used in many industries and in particular in the medical industry. The cladding tests were carried out on three materials: acid-resistant 316L (1.4404) steel with austenitic structure, 2205 (1.4462) steel with duplex structure (austenitic-ferritic) and martensitic steel AMS 5604 (1.4542) precipitation hardened (Table I). The base materials used for the tests were in the form of thin sheets $25 \times 75 \mathrm{~mm}$ and $1 \mathrm{~mm}$ thick.

As an additional material for cladding, both methods used nickel-based wire QuNi41 used mainly for welding cast iron and low and high alloy steels, and chromium-nickel wire QuMed4316 intended for welding/cladding austenitic steels. The QuMed4316 alloy is used, among others for welding tool components used in the medical industry [22]. These materials were provided in the form of $0.5 \mathrm{~mm}$ wire by MEPAC. The chemical composition of the cladding binders used is shown in table II.

Table III summarizes the hardness of the base materials used and the materials applied based on manufacturers' catalog data.

Table I. The chemical composition of the base materials [19, 20, 21]

\begin{tabular}{|c|c|c|c|c|c|c|c|c|c|c|}
\hline \multicolumn{11}{|c|}{ Stal 316L (1.4404) / Steel 316L (1.4404) } \\
\hline Element & $\mathrm{C}$ & $\mathrm{Cr}$ & $\mathrm{Mn}$ & $\mathrm{Ni}$ & $\mathrm{Si}$ & Mo & $\mathrm{P}$ & $S$ & $\mathrm{~N}$ & $\mathrm{Fe}$ \\
\hline$[\%]$, wt. & $<0.03$ & $16.5 \div 18.5$ & $<2.0$ & $10.0 \div 13.0$ & $<1.0$ & $2.0 \div 2.5$ & $<0.045$ & $<0.015$ & $<0.015$ & Rest \\
\hline \multicolumn{11}{|c|}{ Stal 2205 (1.4462) / Steel 2205 (1.4462) } \\
\hline Element & $\mathrm{C}$ & $\mathrm{Cr}$ & $\mathrm{Mn}$ & $\mathrm{Ni}$ & $\mathrm{Si}$ & Mo & $\mathrm{P}$ & $S$ & $\mathrm{~N}$ & $\mathrm{Fe}$ \\
\hline$[\%]$, wt. & $<0.03$ & $21.0 \div 23.0$ & $<2.0$ & $4.5 \div 6.5$ & $<1.0$ & $2.5 \div 3.5$ & $<0.035$ & $<0.015$ & $0.10 \div 0.22$ & Rest \\
\hline \multicolumn{11}{|c|}{ Stal 5604 (1.4542) / Steel 5604 (1.4542) } \\
\hline Element & $\mathrm{C}$ & $\mathrm{Cr}$ & $\mathrm{Mn}$ & $\mathrm{Ni}$ & $\mathrm{Si}$ & $\mathrm{Cu}$ & $\mathrm{P}$ & $S$ & $\mathrm{Nb}$ & $\mathrm{Fe}$ \\
\hline [\%], wt. & $<0.07$ & $15.0 \div 17.5$ & $<1.0$ & $3.0 \div 5.0$ & $<1.0$ & $3.0 \div 5.0$ & $<0.04$ & $<0.03$ & $0.15 \div 0.45$ & Rest \\
\hline
\end{tabular}

Table II. The chemical composition of filler metals [22]

\begin{tabular}{ccccccc}
\hline \multicolumn{7}{c}{ Stop QuMed4316 / QuMed4316 alloy } \\
\hline Element & $\mathrm{C}$ & $\mathrm{Ni}$ & $\mathrm{Mn}$ & $\mathrm{Cr}$ & $\mathrm{Si}$ & $\mathrm{Fe}$ \\
{$[\%]$, wt. } & 0.02 & 9.5 & 1.75 & 19 & 0.85 & Rest \\
& \multicolumn{7}{c}{ Stop } & QuNi41 / & QuNi41 alloy & & \\
\hline Element & $\mathrm{C}$ & $\mathrm{Ni}$ & $\mathrm{Mn}$ & $\mathrm{Ti}$ & $\mathrm{Fe}$ & \\
{$[\%]$, wt. } & 0.1 & 55 & 3.5 & + & rest & \\
\hline
\end{tabular}

Table III. Hardness of used materials [20, 21, 23, 24]

\begin{tabular}{cccccc}
\hline Material & 2205 & 316L & 5604 & QuNi41 & QuMed4316 \\
\hline Hardness HB & 293 & 200 & 388 & 190 & - \\
Hardness HV & 309 & 210 & 401 & 200 & 170 \\
\hline
\end{tabular}




\section{Research characteristics}

The clad welds were made for six different material pairs consisting of 3 base materials $(316 \mathrm{~L}, 2205$, 5604) and 2 additional materials (QuNi41, QuMed4316) using the microTIG method and the laser method.

As part of the tests, a number of clad welds with a variable number of layers (from 1 to 3) were performed. When making multi-layer clad welds, the lower layers (towards the base material) consisted of more beads. In addition, multi-pass clad welds were made so that the individual beads partially overlapped. In the case of microTIG cladding, it was not always possible to melt the entire cross-section of the wire of the additional material with one discharge pulse. In this situation, it was necessary to use two pulses to melt the binder. In most tests the clad weld's length did not exceed $12 \mathrm{~mm}$. Figures 5 and 6 show the appearance of typical clad welds obtained by laser and microTIG methods respectively.

The clad welds obtained with the use of a pulse laser were characterized by an esthetic and regular face. Compared to the clad welds obtained using the microTIG method, they were more compact (Fig. 5), with a smaller scale width resulting from a smaller cladding step. No incompatibilities were observed on the clad welds surfaces.

In the case of the microTIG method, the clad weld's face was irregular (Fig. 6). Craters were visible on the face. The clad weld had a greater width and a smaller riser in relation to the layers obtained by the laser method. A greater amount of spatter was observed during cladding with the microTIG method.

Macroscopic analysis of all layers obtained allowed the selection for further tests of only those samples that ensured obtaining the correct layers. The main criteria for the assessment of the layers when selecting them for subsequent tests were the regularity of the clad weld's face and the minimum number of surface defects such as craters, cracks and splinters. The next part of the work presents the results of testing 6 selected clad welds ( 3 for each of the cladding methods used). Tables IV and V contain information on samples and parameters at which they were made for the microTIG method and the laser method, respectively.

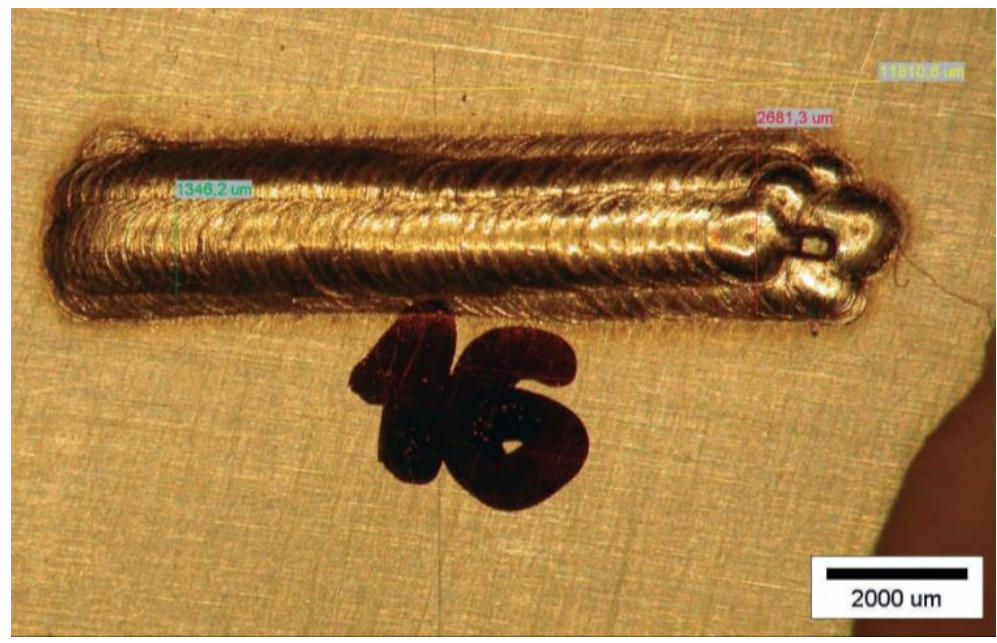

Fig. 2. Macrostructure of a triple-layer clad weld made with a pulse laser on the surface of 2205 duplex steel with QuNi41 filler metal, x10

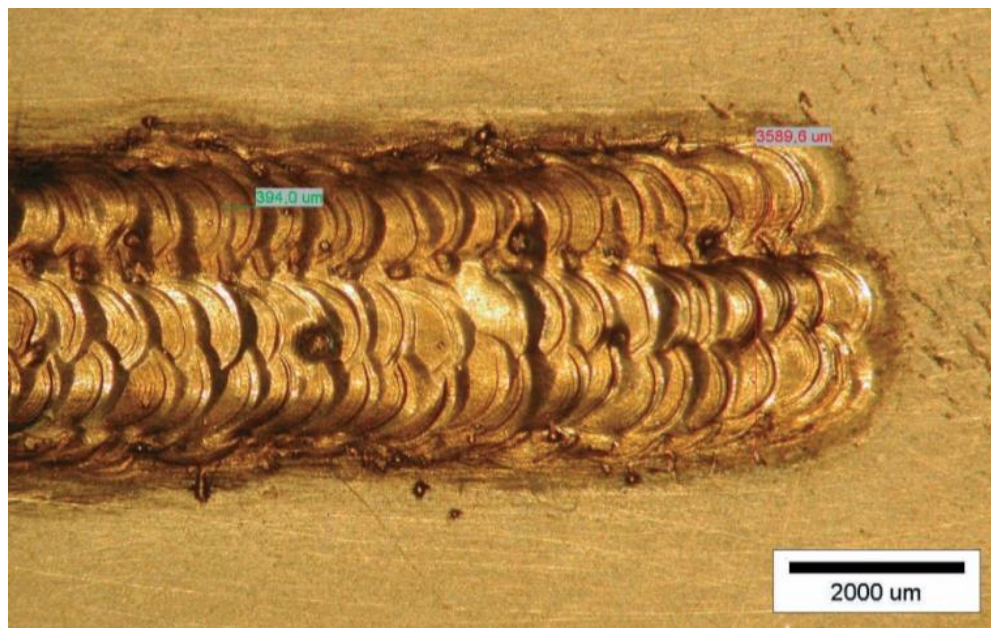

Fig. 3. Macrostructure of a double-layer clad weld made with microTIG method on the surface of 316L steel, with QuMed4316 filler metal, x10 
The next part of the work presents the results of the comparison of laser and microTIG cladding effects for the same pairs of base materials and clad welds.

Table IV. Parameters of the microTIG cladding process

\begin{tabular}{ccccc}
\hline Test No. & Substrate material & Filler metal & Impulse power [\%] & Pulse duration [ms] \\
\hline 1 & 316L & QuNi41 & 50 & 4 \\
3 & Duplex 2205 & QuNi41 & 50 & 4 \\
5 & AMS 5604 & QuNi41 & 50 & 4 \\
\hline
\end{tabular}

Table V. Parameters of the laser cladding process

\begin{tabular}{ccccc}
\hline Test No. & Substrate material & Filler metal & Impulse power [\%] & Pulse duration [ms] \\
\hline 2 & 316L & QuNi41 & 45 & 6 \\
4 & Duplex 2205 & QuNi41 & 65 & 6 \\
6 & AMS 5604 & QuNi41 & 50 & 6 \\
\hline
\end{tabular}

\section{Substrate material - 316L, clad weld - QuNi41}

Metallographic specimens were prepared from selected samples (all samples were digested with the Mi16 solution), which were the subject of metallographic tests, and measurements of sample hardness were made. The purpose of microscopic research was to reveal the microstructure together with the degree of dilution of the clad weld with the base material, determining the heat affected zone and measuring the geometry of the obtained clad welds.

\section{Microstructure}

For comparison of the clad weld microstructure obtained with the microTIG and laser methods, QuNi41 alloy layers obtained on a 316L steel substrate were selected. The samples were: 1 (microTIG) and 2 (laser) from tables IV and V. It can be seen in figure 8 that the clad weld made with a pulse laser has a greater thickness compared to that made with the microTIG method (Fig. 7), respectively $500 \mu \mathrm{m}$ and $250 \mu \mathrm{m}$. However, the width of the clad welds' bead was comparable and in both cases was about $850 \mu \mathrm{m}$. In the discussed samples no heat affected zone (HAZ) was more clearly observed.

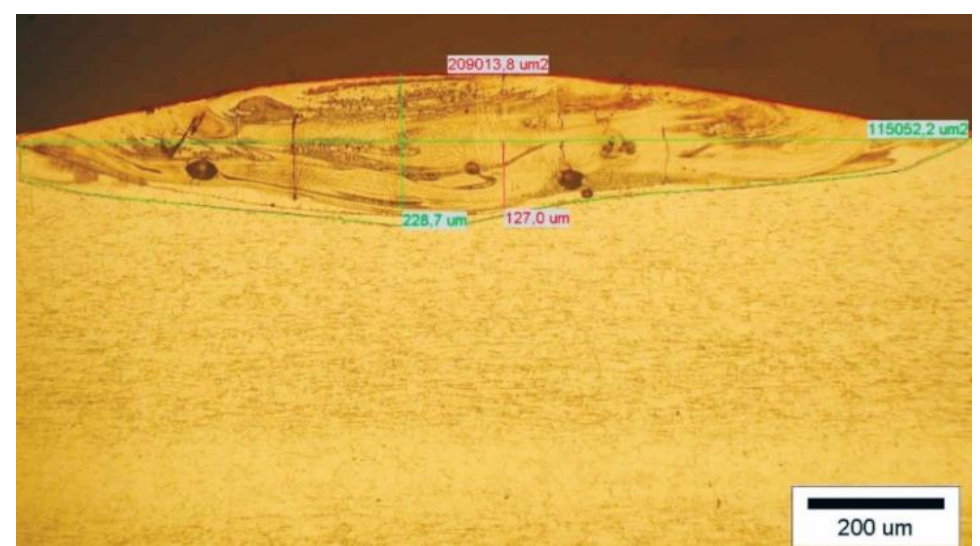

Fig. 4. Sample 1; Single-layer (single-pass) clad weld made with mikroTIG method, x100

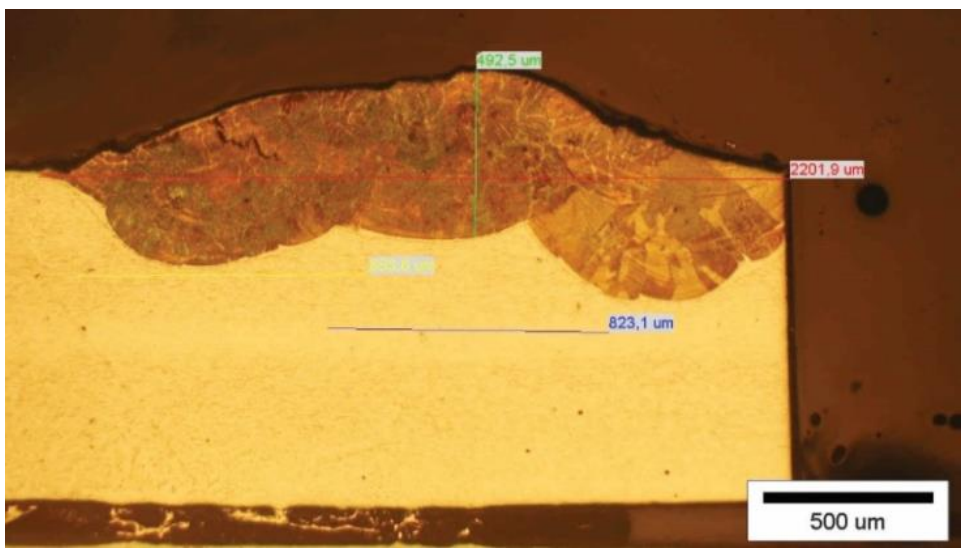

Fig. 5. Sample 2; Single-layer (triple-pass) clad weld made with pulse laser, x50 


\section{Hardness}

Hardness measurements were carried out using the Vickers method in accordance with PN-EN ISO 6507-1: 2018-5, using a $0.981 \mathrm{~N}$ load. Hardness was measured in a direction perpendicular to the surface. The value of each measuring point in the graphs (Figs. 9, 12 and 15) is the arithmetic mean of the four measurements. Error bars represent standard deviations from the mean with an assumed confidence level of $95 \%$. The reference point for each measurement was the line of clad weld penetration into the substrate, and the distance between the imprints was not less than $70 \mu \mathrm{m}$. For samples marked 1 and 2, the results of hardness measurements are shown in figure 9. The average hardness of the clad weld made using both the microTIG method and using a laser was approximately $160 \mathrm{HV}$. The hardness of the 316L steel substrate is also similar for both methods, and the analysis of the hardness results and data contained in table III can conclude that the type of heat source used does not significantly affect the change in the hardness of the substrate. This fact is in line with previous observations proving the lack of visible HAZ. The hardness of the clad weld for sample 2 is approximately constant over the entire thickness of the layer.

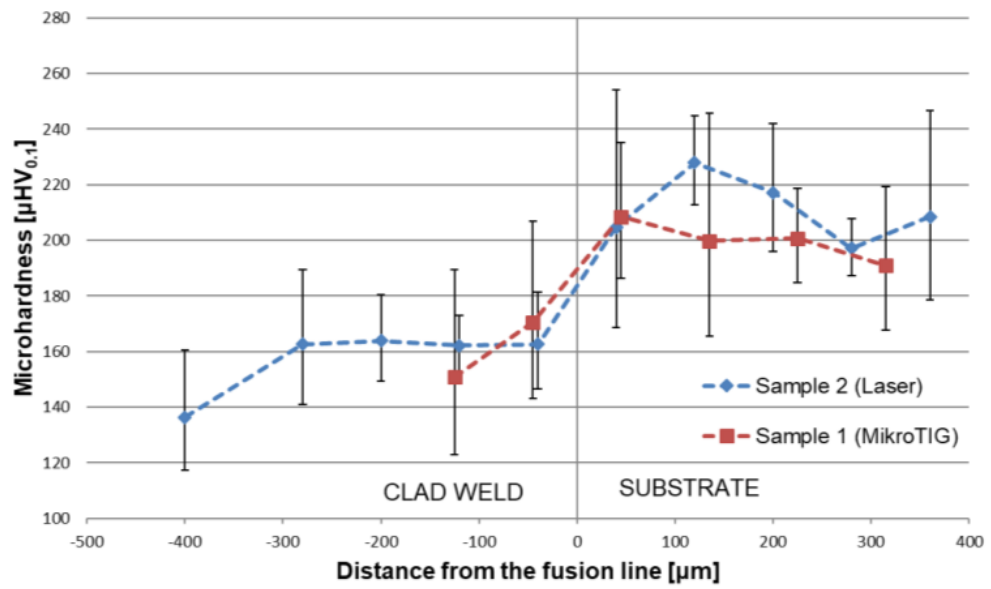

Fig. 6. Distribution of hardness in QuNi41 clad welds produced by the microTIG and laser method on a 316L steel substrate

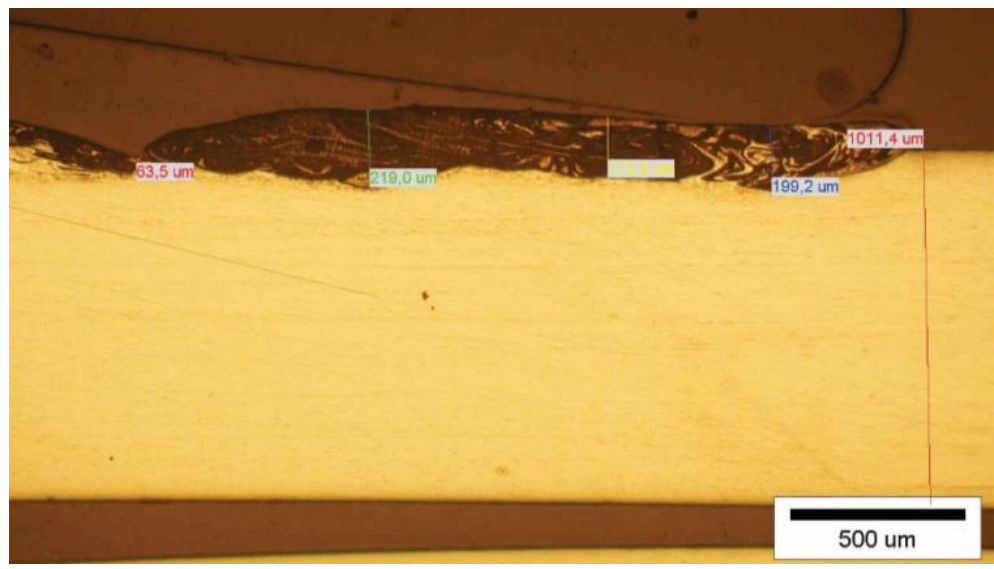

Fig. 7. Sample 3; Single-layer (triple-pass) clad weld made with mikroTIG method, x50

\section{Substrate material - 2205 duplex, clad weld - QuNi41 Microstructure}

The next pair analyzed - samples 3 and 4, included clad welds from QuNi41 alloy made on duplex 2205 steel. The microstructures of QuNi41 clad welds obtained by the microTIG and laser methods are shown in figures 10 and 11. The average thickness of the clad weld made using the microTIG method was about $200 \mu \mathrm{m}$, and in the case of a pulsed laser approx. $500 \mu \mathrm{m}$. The difference in the structure of the clad welds is also visible. The laser allowed to obtain a homogeneous structure, while the structure obtained using the microTIG method is mosaic. The heat affected zone in both tested samples is practically imperceptible. 


\section{Hardness}

Measurements of the hardness of clad welds in samples 3 and 4 showed almost identical hardness of the base material, which compared to the catalog hardness of this steel is on average $20 \mathrm{HV}$ lower (regardless of the method used). In the case of clad weld in sample 4 made with pulse laser, its hardness is approximately constant over the entire cross-section, which cannot be observed in sample 3 made using the microTIG method. In figure 10, the light and dark phases can be observed in the clad weld, which is probably the result of insufficient dilution of the base material with the additional material. The light phase hardness is significantly different from that of the dark phase, as shown in figure 12 for the first two points. Due to large differences in hardness, standard deviation bars were not marked for these two measuring points.

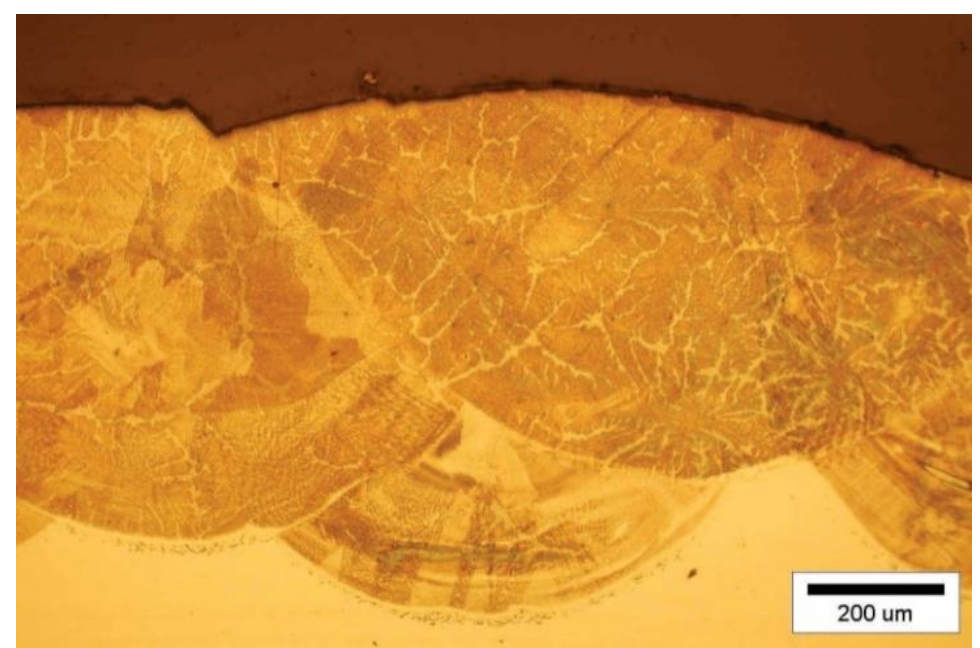

Fig. 11. Sample 4; Part of a double-layer clad weld made with pulse laser, x100

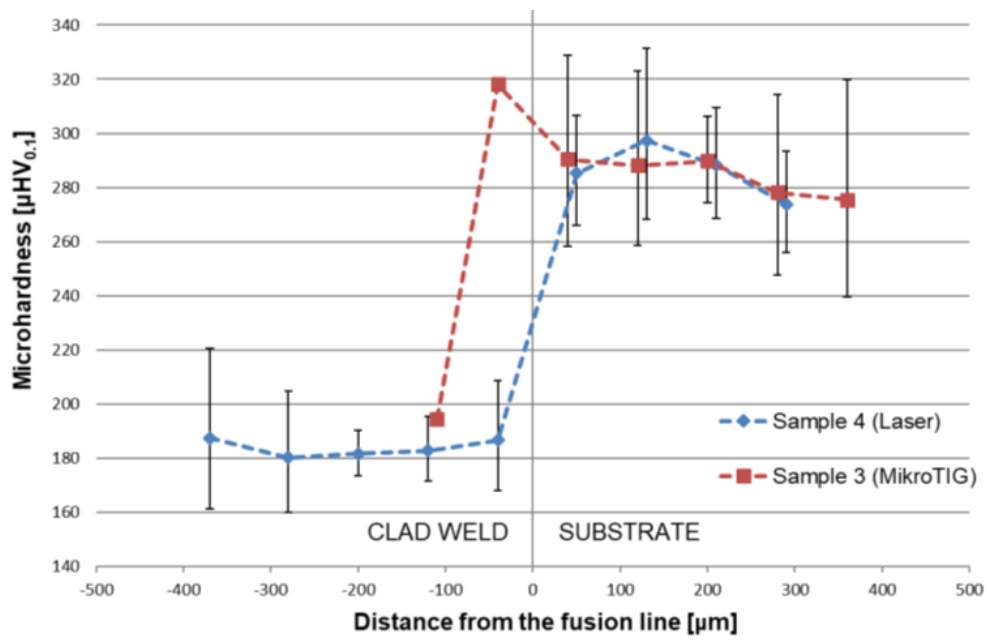

Fig. 8. Distribution of hardness in QuNi41 clad welds produced by the microTIG and laser method on a 2205 (duplex) steel substrate

\section{Substrate material - AMS 5604, clad weld - QuMed4316}

\section{Microstructure}

The last comparison concerns the material pair of the AMS 5604 steel substrate and the QuMed4316 alloy clad weld. Sample 5 (Fig. 13) presents the effect of cladding with the microTIG method, and sample 6 (Fig. 14) with pulsed laser cladding. The clad welds in both cases have a single-phase structure and show increased resistance to etching (with respect to the base material). In the area of the substrate material of the sample 6 cladded with a pulsed laser, the heat affected zone is clearly marked. Most likely, this is due to the absorption of a large amount of heat by the substrate material, because sample 6 has been subjected to multiple heat cycles (double-layer multi-pass clad weld). In the case of sample 5, the heat affected zone is also visible, but not as extensive as in the case of sample 6 . The HAZ range is about $100 \mu \mathrm{m}$ for sample 5 cladded with the microTIG method and $230 \mu \mathrm{m}$ for sample 6 cladded with laser. 


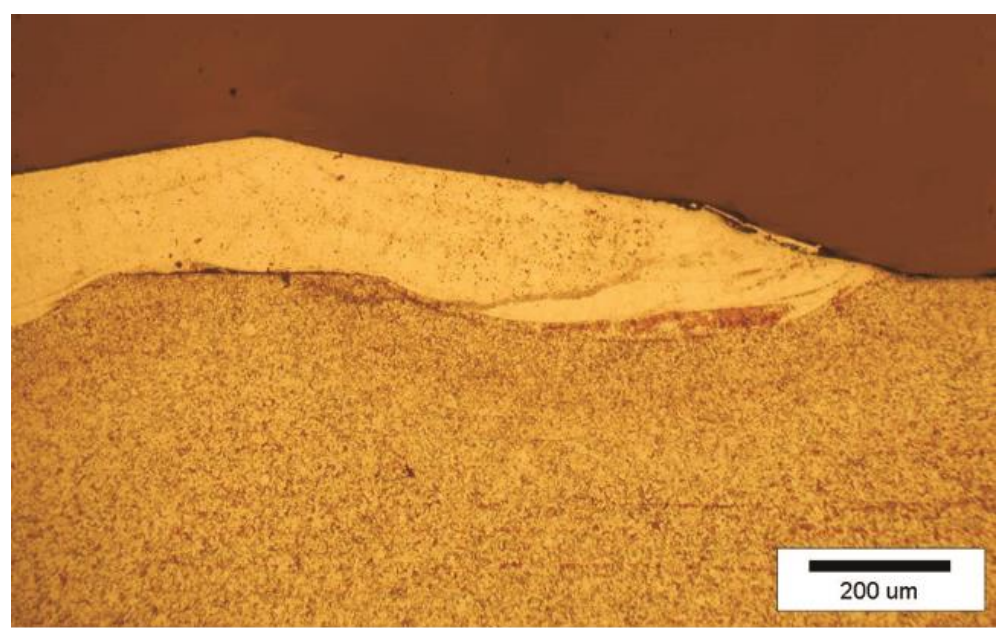

Fig. 9. Sample 5; Part of a single-layer (two-pass) clad weld made with the microTIG method, x100

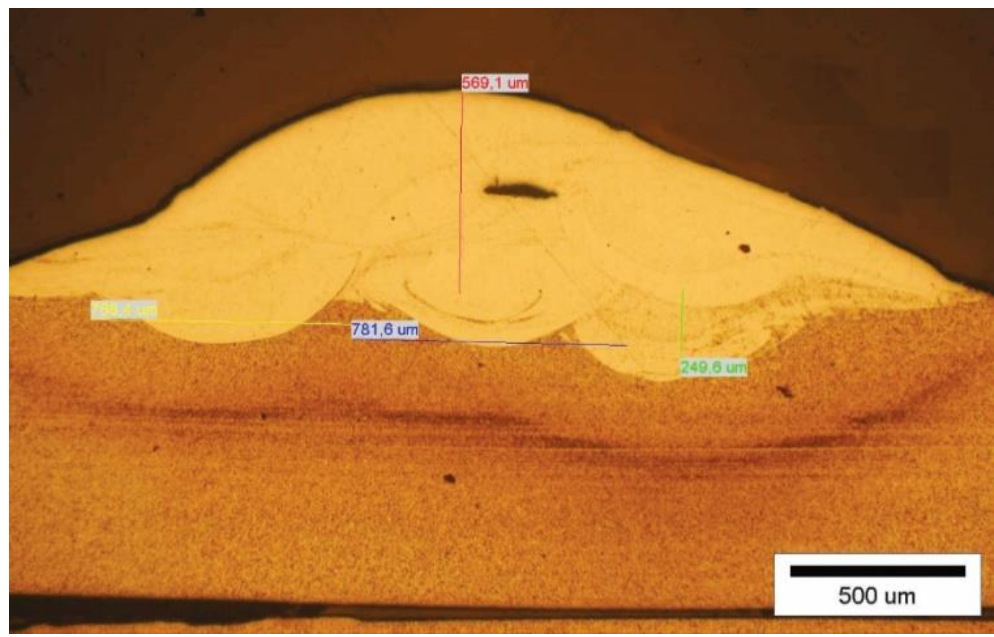

Fig. 10. Sample 6; Double-layer (multi-pass) clad weld made with pulse laser, x50

\section{Hardness}

Despite the clear difference in the size of both clad welds, the hardness of individual structures created using the laser and microTIG methods is similar. The hardness of the clad weld over its entire thickness was about $225 \mathrm{HV}$. Much larger discrepancies are observed in the case of the hardness distribution of the base material. In the case of laser cladding, the hardness of the base material increases as it moves away from the clad weld's fusion line into the substrate (Fig. 15). A large amount of heat supplied to the material sensitive to the thermal cycle caused a decrease in hardness in the HAZ, to a depth of approx. $200 \mu \mathrm{m}$ below the fusion line. In addition to HAZ, hardness stabilizes around the catalog value for AMS 5604 steel. The hardness of the substrate material in the case of the microTIG sample is approximately constant throughout the entire tested section (up to approx. $400 \mu \mathrm{m}$ below the fusion line). Comparing the conditions under which these two cladding tests were carried out, some inconsistency can be found. The base material, which absorbed more heat (sample 6 - double-layer clad weld), has a higher hardness (and at the same time close to the catalog value) than the one whose heat absorption was lower (sample 5). The expected effect should be the opposite, i.e. less heat should cause milder changes in hardness. It is difficult to clearly explain because the amount of penetration obtained in the process of laser micro-cladding is influenced by a large number of factors, among others laser power, time and shape of laser pulsation, diameter of laser spot, size of beads overlapping, or cladding speed [25]. For example, the faster the cladding speed is, the material needs to cool down shorter and its temperature will increase until the cladding is over. The melted material becomes "softer" and facilitates the penetration of the laser beam, which especially takes place in the case of thin materials. In addition, the thermal cycle of heating and cooling leads to changes in the microstructure of the material, e.g. causing an increase in its hardness, which in turn may hinder further penetration of the laser beam. 


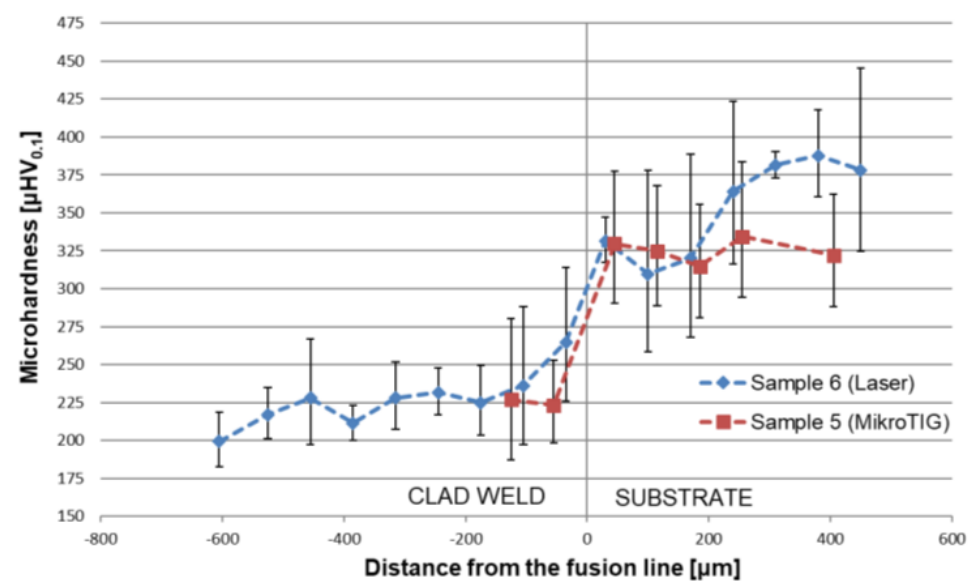

Fig. 11. Distribution of hardness in QuMed4316 clad welds produced by the microTIG and laser method on a AMS 5604 steel substrate

\section{Dilution ratio}

The value of dilution ration Up was calculated for all analyzed samples with clad welds on the basis of cross-sectional area measurements. For this purpose, the known relation described by equation 1 [26] was used, explanations of symbols are presented in figure 16. For tested samples, calculated values of dilution ratio are given in table VI.

$$
U_{p}=\frac{A_{w}}{A_{w}+A_{n}}
$$

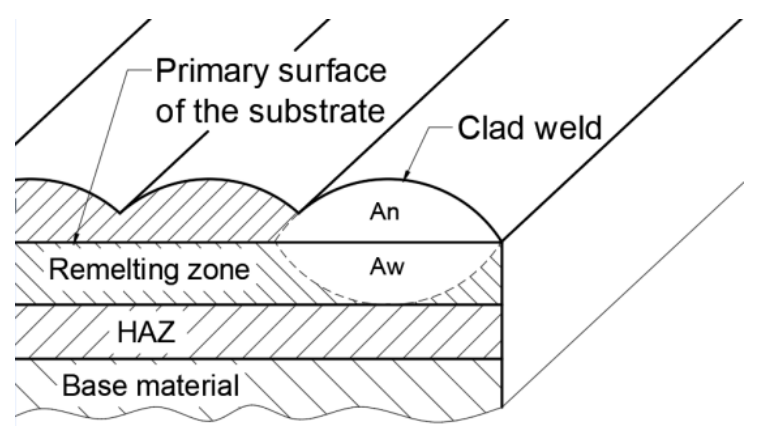

Fig. 16. Scheme of clad weld cross section

The data presented in Table VI show that the dilution ratio reaches values in the range of $44 \div 55 \%$ for QuNi41 clad welds on 316L and Duplex 2205 steel substrates, while for QuMed4316 clad welds on AMS5604 steel it is lower in the range of $25 \div 29 \%$. After analyzing the obtained results, it cannot be unequivocally determined which of the cladding methods used allows achieving a smaller degree of dilution. For example, comparing the value of the dilution ratio for samples 3 and 4 , it can be seen that in the case of laser cladding despite a double-layer clad weld, the share of the substrate material in the cladding is greater than in the case of the single-layer clad weld obtained by the microTIG method. This distribution of results may be affected by the type of heat source used and the resulting different nature of energy concentration, or the difficulties associated with providing continuous and constant dosing of additional material during making the entire bead.

Table VI. Dilution ratio calculated for the tested samples

\begin{tabular}{cccccc}
\hline $\begin{array}{c}\text { Sample } \\
\text { designation }\end{array}$ & Method & $\begin{array}{c}\text { Substrate } \\
\text { material }\end{array}$ & $\begin{array}{c}\text { Filler } \\
\text { metal }\end{array}$ & $\begin{array}{c}\text { Number of clad } \\
\text { weld layers }\end{array}$ & $\begin{array}{c}\text { Dilution ratio } \\
\mathbf{U}_{\mathbf{p}}\end{array}$ \\
\hline 1 & MikroTIG & $316 \mathrm{~L}$ & QuNi41 & 1 & $55.05 \%$ \\
2 & Laser & $316 \mathrm{~L}$ & QuNi41 & 1 & $44.48 \%$ \\
3 & MikroTIG & Duplex 2205 & QuNi41 & 1 & $45.01 \%$ \\
4 & Laser & Duplex 2205 & QuNi41 & 2 & $54.98 \%$ \\
5 & MikroTIG & AMS 5604 & QuMed4316 & 1 & $29.77 \%$ \\
6 & Laser & AMS 5604 & QuMed4316 & 2 & $25.93 \%$ \\
\hline
\end{tabular}




\section{Summary}

The paper presents a comparison of two methods of cladding in micro-areas using the microTIG method and a laser beam. Tests were carried out on steel substrates (316L, Duplex 2205, AMS5604) with two alloys QuNi41 and QuMed4316, which can be used in the medical industry as regenerative layers for tools.

The results of the microstructure tests show that the clad welds made using the microTIG method and with the use of an impulse laser show considerable variation. This may be due to the different amount of energy supplied to the machining area in an impulse during cladding. This is due to the different nature of the heat sources used and the heat transfer to the material being treated. Compared to the welding electric arc, the laser beam has a much higher concentration (density) of energy, which has a direct effect on the shape of the clad weld (it is narrower, with deeper penetration).

In each of the presented laser samples, the depth of penetration of the clad weld into the substrate was much greater than in the microTIG method. It can be assumed that in the case of the performed tests, the parameters of the laser cladding process were not optimal, which could have influenced the obtained clad weld's shape. Generally, laser cladding allows to obtain a low level of dilution, among others thanks to the ability to accurately control both the position and the parameters of the laser beam. On the other hand, by cladding with the microTIG method, even in conditions of not optimizing the parameters of the cladding process, it is possible to obtain a clad weld characterized by a small content of the base material. In turn, the favor of laser technologies is the high repeatability of the process, which is difficult to obtain with the microTIG method.

Additional materials in the form of QuNi41 and QuMed4316 alloys were selected for cladding in order to examine the possibility of their application in terms of surface regeneration of objects made of special steels, i.e. 316L, 2205 and 5604. The main criterion for assessing clad welds was the possibility of obtaining a layer with the least amount of defects. The laser beam, irrespective of the type of material pair being tested, ensures that the clad weld penetrates into the substrate material along its entire width. The number of defects in the form of cracks and porosity is minimal. By welding with the microTIG method, there is a much greater chance of the occurance of welding defects or incompatibilities.

The QuMed4316 alloy is a more promising material in surface regeneration applications than the QuNi41 alloy. QuMed4316 alloy provides much better dilution with the base material and, as a result, forms a single-phase clad weld, regardless of the method of cladding used. Compared to the QuNi41 alloy, it creates a layer of higher hardness, which may contribute to increased resistance to wear of the surface. It was also observed that the clad welds made of QuMed4316 alloy are more resistant to chemical etching.

In the process of cladding QuNi41 alloy onto a 316L and 2205 steel substrate, there is a tendency to form cracks in the clad weld area, regardless of the heat source used. The different chemical composition of this alloy from cladding materials, in conditions of very intense heating and cooling of the machining area, prevents accurate dilution of the materials forming the clad weld, which may result in the formation of a multi-phase structure, e.g. in sample 3. The advantage of using the QuNi41 alloy compared to the QuMed4316 alloy is lower energy input required to melt a unit of volume of material, which results in good penetration into the substrate of QuNi41 clad welds. A larger amount of heat needed to melt the QuMed4316 alloy, under the conditions of cladding with a low-power heat source (microTIG), may result in defects in the form of incomplete fusion (as in sample 5).

In the case of microTIG cladding, no noticeable effect on the properties of the substrate material was observed. No significant changes in the hardness of the substrate material were noted in any of the tested material pairs, and no clearly marked heat affected zone was observed on metallographic specimens.

\section{Final conclusions}

Based on the conducted research, the following conclusions can be drawn:

- The use of the microTIG method for cladding in micro-areas may be an alternative to other methods, such as microplasma or laser. The resulting clad welds from QuNi41 and QuMed4316 alloys on 316L, Duplex 2205 and AMS5604 steel substrates are of good quality.

- Laser cladding of the same materials in the case of the microTIG method ensures that a more uniform clad weld without flaws is obtained, resulting in greater penetration into the substrate material. Obtaining a clad weld with a similar width as in the microTIG method requires the use of more beads and layers.

- The clad welds obtained by laser on 316L and AMS 5604 steel were characterized by higher hardness than in the case of microTIG (on the order of several dozen HV units). For 2205 steel, similar hardness distribution in clad welds was obtained. 
- The degree of dilution of the base material in the clad welds reached values in the range of $25 \div 55 \%$ depending on the materials used, the cladding method and the number of layers.

The research results presented in the paper present the potential opportunities for cladding with the microTIG method and the microscale laser beam, paying particular attention to the strengths and weaknesses of each of these methods. In future works, it would be advisable, especially for the microTIG method, which is still poorly understood, to carry out additional tests to optimize the parameters of the cladding process. It would be desirable to mechanize and automate the process of applying layers with this method to ensure repeatable and stable surface modification conditions.

Author Contributions: conceptualization J.J.; methodology J.J., P.P.; investigation, J.J., P.P; discussion P.P.; writing - original draft preparation P.P.; writing - review and editing J.J., P.P.

Funding: This research received no external funding.

Conflicts of Interest: The authors declare no conflict of interest.

Acknowledgments: The authors of the article would like to thank Mr. Andrzej Radziszewski, the owner of the www.RESURS.pl company, for providing access to the microTIG and laser stations, as well as additional materials for the cladding process.

\section{References}

[1] Chmielewski T., Golański D., The role of welding in the remanufacturing process, Welding International, 2015, Vol. 29(11), 861-864. https://doi.org/10.1080/09507116.2014.937604

[2] Golański D., Chmielewski T., Skowrońska B., Rochalski D., Advanced Applications of Microplasma Welding. Biuletyn Instytutu Spawalnictwa w Gliwicach, 2018, Vol. 62(5), 53-63. https://doi.org/10.17729/ebis.2018.5/5

[3] Ivanov V. A., Kuksenova L. I., Lapteva V. G., Konyzhev M. E., Application of the Microplasma Method for Strengthening of the Near-Surface Layer of Samples Made from Steel 45, Journal of Machinery Manufacture and Reliability, 2008, Vol. 37(3), 278-283. https://doi.org/10.3103/S1052618807060118

[4] Chigrinova N. M., Application of Microplasma Spark Treatments for Creating Stable Heat-Resistant Barriers on the Surface of Jackets of Thermionic Transducers in Nuclear Reactors, Atomic Energy, 2006, Vol. 100(5). https://doi.org/10.1007/S10512-006-0091-7

[5] Buytoz S., Orhan A., Gur A., K., Caligulu U., Microstructural Development of Fe-Cr-C and B4C Powder Alloy Coating on Stainless Steel by Plasma-Transferred Arc Weld Surfacing, Arab J Sci Eng, 2013, 38, 2197-2204, https://doi.org/10.1007/s13369-013-0599-9

[6] Chen J.-H., Hua P.-H., Chen P.-N., Chang C.-M., Chen M.-C., Wu W., Characteristics of multi-element alloy cladding produced by TIG process, Materials Letters, 2008, Vol. 62(16), 2490-2492. https://doi.org/10.1016/j.matlet.2007.12.038

[7] Shan J., Dong W., Tan W., Zhang D., Ren J., Dilution rate and microstructure of TIG arc Ni-Al powder surfacing layer, Frontiers of Mechanical Engineering, 2007, 2(1), 20-24. https://doi.org/10.1007/s11465-007-0003-0

[8] Lucas W., CHAPTER 5 - Micro-TIG welding, Editor(s): W Lucas, In Woodhead Publishing Series in Welding and Other Joining Technologies, TIG and Plasma Welding, Woodhead Publishing, 1990, pp. 62-64, ISBN 9781855730052; https://doi.org/10.1533/9780857093264.1.62

[9] Moradi M., Arabi H., Kaplan A. F. H., An experimental investigation of the effects of diode laser surface hardening of AISI 410 stainless steel and comparison with furnace hardening heat treatment, Journal of the Brazilian Society of Mechanical Sciences and Engineering, 2019, 41:434. https://doi.org/10.1007/s40430-019-1925-2

[10] Ahn Dong-Gyu, Hardfacing Technologies for Improvement of Wear Characteristics of Hot Working Tools: A Review, International Journal of Precision Engineering and Manufacturing, 2013, Vol. 14(7), 1271-1283, https://doi.org/10.1007/s12541-013-0174-z

[11] Baraniecki T., Chlebus E., Dziatkiewisz M., Kędzia J., Reiner J., Wierchioch M., System laserowego mikronapawania proszków metali, Welding Technology Review, 2011, Vol. 83(9), 22-26. https://doi.org/10.26628/wtr.v83i9.505

[12] Jamkamon K., Yamada K., Inoue T., Sekiya K., Tanaka R., Improved Machinability of High Hardened Die Steel by Using Pulsed Laser Surface Treatment, International Journal of Precision Engineering and Manufacturing, 2019, 20:1667-1676. https://doi.org/.1007/s12541-019-00182-1

[13] Młynarczyk P., Depczyński W., Wybrane właściwości powłok regeneracyjnych wykonanych techniką mikrospawania na przykładzie wału korbowego z żeliwa ADI, Logistyka, 2015, Vol. 4, 4947-4953. 
[14] Napadłek W., Burakowski T., Laber A., Analiza Możliwości Zastosowania Mikronapawania Laserowego w Newralgicznych Strefach Zaworów Wylotowych Silników Spalinowych, TRANSCOMP - XIV International Conference, Computer Systems Aided Science, Industry and Transport, 2010, Zakopane.

[15] Freeman R. New welding techniques for aerospace engineering, Welding and Joining of Aerospace Materials Woodhead Publishing Series in Welding and Other Joining Technologies 2012, pp. 3-24. https://doi.org/10.1533/9780857095169.1.1

[16] Das A., Li D., Williams D., Greenwood D., Joining Technologies for Automotive Battery Systems Manufacturing, World Electr. Veh. J., 2018, Vol. 9(2), 22. https://doi.org/10.3390/wevj9020022

[17] Bîrdeanu A.-V., Ciucă C., Puicea A., Pulsed LASER-(micro)TIG hybrid welding: Process characteristics, Journal of Materials Processing Technology, 2012, Vol. 212(4), 890-902. https://doi.org/10.1016/j.jmatprotec.2011.11.014

[18] Burakowski T., Wierzchoń T., Surface Engineering of Metals (in polish) 1995, WNT, Warszawa, ISBN: 83-204-1812

[19] Ikhmayies S. i inni., Mechanical Properties and Behavior of Additive Manufactured Stainless Steel 316L, In Book Characterization of Minerals, Metals, and Materials, Springer, Cham, 2017, 577-583, ISSN: 2367-2696, https://doi.org/10.1007/978-3-319-51382-9

[20] Catalogue of Demark, Available online: https://www.demark.net.pl.

[21] Catalogue of VIRGAMET, Available online: https://virgamet.pl.

[22] Catalogue of MEPAC CZ, Available online: https://www.mepac.cz.

[23] MT-308L (1.4316), Catalogue of „R-Line”, Available online: http://www.r-line.pl.

[24] NiFe-2, Catalogue of „CERTILAS”, Available online: http://www.certilas.nl/en/product/nife-2.

[25] Xue X., Pereira A.B., Amorim J., Liao J., Effects of Pulsed Nd:YAG Laser Welding Parameters on Penetration and Microstructure Characterization of a DP1000 Steel Butt Joint, Metals 2017, 7, 292. https://doi.org/10.3390/met7080292

[26] Steen W., Mazumder J. Laser Material Processing. Springer-Verlag London, 2010, https://doi.org/10.1007/978-184996-062-5 ISBN 978-1-84996-062-5

(C) 2020 by the authors. Submitted for possible open access publication under the terms and conditions of the Creative Commons Attribution (CC BY) license (http://creativecommons.org/licenses/by/4.0/). 